\title{
Socioeconomic barriers to cataract surgery in Nepal: the south Asian cataract management study
}

T Snellingen, B R Shrestha, M P Gharti, J K Shrestha, M P Upadhyay, R P Pokhrel

\begin{abstract}
Background-Previous studies have shown that, despite an increasing availability of cataract surgery, important socioeconomic barriers exist in the acceptance of surgery in many rural areas of south Asia. Nepal has developed a comprehensive national network of eye hospitals but the surgical coverage for the treatment of cataract blind is still low.
\end{abstract}

Aims-To determine the utilisation of cataract surgery and the level of physical and psychosocial impairment and the socioeconomic barriers to surgery in a group of non-acceptors of surgery.

Institutes of Clinical and Community Medicine, University of Troms $ø$, Norway $\mathrm{T}$ Snellingen

Ministry of Health, Ramshapath, Kathmandu, Nepal B R Shrestha

SACMS Programme Office, Institute of Medicine, Kathmandu, Nepal

M P Gharti

BP Koirala Lions Centre for Ophthalmic Studies, Institute of Medicine, Kathmandu, Nepal

J K Shrestha

M P Upadhyay

Nepal Netra Jyothi Sangh, Nepal Eye Hospital, Kathmandu,

Nepal

R P Pokhrel

Correspondence to: Torkel Snellingen, MD, Institute of Community

Medicine, 9037 University of

Tromsø, Norway.

Accepted for publication 3 June 1998

Table 1 Visual function questionnaire

included questions on visual function, quality of life, and socioeconomic variables on acceptance of cataract surgery. The quality of life questionnaire was based on the field validated protocol addressing the impact of visual impairment on physical and psychosocial functions. The questionnaire was adapted to the local conditions after pretesting. Data were analysed by degree of visual impairment. Results-Of 319 cataract patients identified only $45.5 \%$ accepted surgery, with men accepting surgery more readily than women $(\mathrm{RR}=1.31 ; 95 \% \mathrm{CI}=1.04-1.67)$ because of a significantly greater acceptance of surgery in men in the non-blind group. The acceptance rate was significantly higher in the blind group $(R R=1.74$; 95\%CI $=1.36-2.22)$ compared with those patients having impairment of vision and severe loss of vision. Of 96 non-acceptors interviewed only a further $13 \%$ accepted surgery after a second counselling. The most frequent reasons given for not accepting surgery were economic (48\%) and logistical $(44.8 \%)$ constraints followed by fear of surgery (33.3\%) and lack of time $(\mathbf{1 8 . 8 \%})$. Half of the subjects complained of problems with self care but only $10 \%$ needed help for their most basic every day activities. $17.7 \%$ said they needed help to visit neighbours and $26 \%$ needed help to attend the field or market.

Conclusions-It was found that in this population with a majority of patients with severe vision loss and blind, even when offered transport and free surgery the utilisation of cataract surgery is below $60 \%$. Medicine tends to be prescriptive based on technological advances that it is able to offer. Medical practice needs to develop a more holistic understanding of the needs of the communities cultivating a greater capability to analyse the role of cultural, social, and economic factors when planning medical services for the population.

(Br f Ophthalmol 1998;82:1424-1428)

Worldwide cataract blindness continues to be the major cause of all blindness. It is estimated that $41.8 \%$ of all global blindness is caused by cataract. ${ }^{1}$ The WHO-NPCB (National Programme for Control of Blindness) survey (1986-9) revealed that in India alone cataract is responsible for $81 \%$ of severe vision loss and blindness. ${ }^{2}$ It is estimated that 9.7 million have severe visual impairment (less than 6/60) and 4.3 million are blind (less than $3 / 60$ ) due to bilateral cataract. By the year 2020 the elderly population of 60 years and above is expected to double from today's number increasing the number of blind even more. ${ }^{3}$ It is becoming clear, however, that strategies for reducing the cataract backlog are related not just to surgical considerations but equally important are issues related to levels of education, economic wealth, and occupation of the cataract patient and his or her guardian(s). Studies in India have shown that despite the rapid increase in the availability of quality services resulting in an increased awareness of the benefits of cataract surgery, surgical uptake is still low in the rural segments

\begin{tabular}{|c|c|c|}
\hline Variable & Question & Grading \\
\hline $\begin{array}{l}\text { Self assessment of vision } \\
\text { Visual function: }\end{array}$ & In general, would you say your vision (with glasses if you are wearing them) is: & very good, 1 ; good, 2 ; fair, 3 ; poor, 4 \\
\hline Limitation of daily activities & To what extent does your eye sight limit you in your daily activities? & not at all, 1 ; a little, 2 ; quite a bit, 3 ; a lot, 4 \\
\hline Recognition of face & Do you have a problem recognising the face of a person standing near you? & not at all, 1 ; a little, 2 ; quite a bit, 3 ; a lot, 4 \\
\hline Identifying small objects & $\begin{array}{l}\text { Do you have a problem recognising small or minute objects (such as grains or } \\
\text { the lines on your hand)? }\end{array}$ & not at all, 1 ; a little, 2 ; quite a bit, 3 ; a lot, 4 \\
\hline Dark adaptation & Do you have a problem adjusting to darkness after being in bright light? & not at all, 1 ; a little, 2 ; quite a bit, 3 ; a lot, 4 \\
\hline Light adaptation & Do you have a problem adjusting to brightness after being in a dark place? & not at all, 1 ; a little, 2 ; quite a bit, 3 ; a lot, 4 \\
\hline
\end{tabular}


Table 2 Distribution of acceptors of surgery by vision groups and sex. Initial screening

\begin{tabular}{|c|c|c|c|c|c|c|c|c|c|}
\hline & \multicolumn{3}{|c|}{ All $(<6 / 18)$} & \multicolumn{3}{|c|}{ Visual impairment and severe vision loss $(<6 / 18-3 / 60)$} & \multicolumn{3}{|c|}{ Blind $(<3 / 60)$} \\
\hline & \multicolumn{3}{|c|}{ Acceptors } & \multicolumn{3}{|c|}{ Acceptors } & \multicolumn{3}{|c|}{ Acceptors } \\
\hline & No & $n(\%)$ & $R R(95 \% C I)^{\star}$ & No & $n(\%)$ & $R R(95 \% C I)^{\star}$ & No & $n(\%)$ & $R R(95 \% C I)^{*}$ \\
\hline Male & 103 & $56(54.4)$ & $1.31(1.04-1.67)$ & 64 & $30(46.9)$ & $1.72(1.16-2.57)$ & 39 & $26(66.7)$ & $1.17(0.89-1.55)$ \\
\hline Female & 216 & 89 (41.5) & Ref & 114 & $31(27.2)$ & Ref & 102 & $58(56.9)$ & Ref \\
\hline Total & 319 & $145(45.5)$ & $\mathrm{p}=0.027$ & 178 & $61(34.3)$ & $\mathrm{p}=0.008$ & 141 & $84(59.6)$ & $\mathrm{p}=0.29$ \\
\hline
\end{tabular}

^Male/female RR.

of the society owing to substantial socioeconomic barriers to accepting surgery. ${ }^{5}$

In Nepal cataract is still the most important cause of blindness despite the presence of a network of eye hospitals distributed throughout the country. ${ }^{6}$ One may therefore assume that one of the reasons for the high cataract blindness prevalence is the low utilisation of the services. The main aim of this study was to describe the surgical uptake in a rural community serviced by a local eye hospital, determine possible reasons for non-acceptance of surgery, and compare these findings with the findings of other current and previous studies. We were also interested to explore impairment of visual and psychosocial functions and whether these influenced the decision making process of accepting surgery.

Table 3 Self reported visual function * of the subjects included in interview (non-acceptors) by vision group

\begin{tabular}{|c|c|c|c|}
\hline & $\begin{array}{l}\text { Visual impairment and severe } \\
\text { vision loss }(<6 / 18-3 / 60)(n=47)\end{array}$ & $\begin{array}{l}\text { Blind }(<3 / 60) \\
(n=49)\end{array}$ & \\
\hline & Mean score (SD) & Mean score (SD) & $p$ Valuet \\
\hline Limitation of daily activities & $2.62(0.87)$ & $3.27(0.86)$ & 0.0004 \\
\hline Recognition of faces & $1.92(1.00)$ & $3.04(1.00)$ & $<0.0001$ \\
\hline Identifying small objects & $2.43(1.16)$ & $3.33(0.85)$ & $<0.0001$ \\
\hline Dark adaptation & $2.74(1.0)$ & $3.37(0.78)$ & 0.0008 \\
\hline Light adaptation & $1.98(0.87)$ & $2.92(0.93)$ & $<0.0001$ \\
\hline
\end{tabular}

${ }^{\star}$ Categories: 1 , not at all; 2 , a little; 3 , quite a bit; 4 , a lot; †test between vision groups.

Table 4 Reasons reported for not accepting surgery by visual categories

\begin{tabular}{|c|c|c|c|c|}
\hline & $\begin{array}{l}\text { All }(<6 / 18) \\
(n=96)\end{array}$ & $\begin{array}{l}\text { Visual impairment } \\
\text { and severe vision loss } \\
(<6 / 18-3 / 60)(n=47)\end{array}$ & $\begin{array}{l}\text { Blind }(<3 / 60) \\
(n=49)\end{array}$ & \\
\hline & $n(\%)$ & $n(\%)$ & $n(\%)$ & $R R(95 \% C I)^{*}$ \\
\hline \multicolumn{5}{|l|}{ Economic } \\
\hline patient & $48(50.0)$ & $20(42.6)$ & $28(57.1)$ & $1.34(0.89-2.03)$ \\
\hline guardian & $46(50.6)$ & $18(40.9)$ & $28(59.6)$ & $1.46(0.95-2.23)$ \\
\hline agreement† & 0.88 & 0.93 & 0.83 & \\
\hline \multicolumn{5}{|l|}{ Logistics } \\
\hline patient & $43(44.8)$ & $23(48.9)$ & $20(40.8)$ & $0.83(0.53-1.30)$ \\
\hline guardian & $36(39.6)$ & $18(40.9)$ & $18(38.3)$ & $0.94(0.56-1.56)$ \\
\hline agreement & 0.81 & 0.82 & 0.81 & \\
\hline \multicolumn{5}{|l|}{ Fear } \\
\hline patient & $32(33.3)$ & $16(34.0)$ & $16(34.0)$ & $0.96(0.65-1.69)$ \\
\hline guardian & $33(36.3)$ & $18(40.9)$ & $15(31.9)$ & $0.78(0.45-1.35)$ \\
\hline agreement & 0.82 & 0.75 & 0.89 & \\
\hline \multicolumn{5}{|l|}{ Time } \\
\hline patient & $18(18.8)$ & $12(25.5)$ & $6(12.2)$ & $0.48(0.20-1.17)$ \\
\hline guardian & $11(12.1)$ & $7(15.9)$ & $4(8.5)$ & $0.53(0.17-1.70)$ \\
\hline agreement & 0.89 & 0.91 & 0.87 & \\
\hline \multicolumn{5}{|l|}{ No faith } \\
\hline patient & $13(13.5)$ & $8(17.0)$ & $5(10.2)$ & $0.60(0.21-1.70)$ \\
\hline guardian & $4(4.4)$ & $2(4.6)$ & $2(4.3)$ & $1.07(1.16-7.26)$ \\
\hline agreement & 0.90 & 0.86 & 0.94 & \\
\hline \multicolumn{5}{|l|}{ Adequate vision } \\
\hline patient & $13(13.5)$ & $10(21.3)$ & $3(6.1)$ & $0.29(0.08-0.95)$ \\
\hline guardian & $10(11.0)$ & $7(15.9)$ & $3(6.4)$ & $0.40(0.11-1.46)$ \\
\hline agreement & 0.91 & 0.84 & 0.98 & \\
\hline
\end{tabular}

*Test between vision groups; †number of patients and guardians with equal responses/total.
Subjects and methods

The study was conducted from October 1992 to January 1993 in the mid western development region in the low lands of Nepal just north of the Ganges plain. There is a metalled road going across the lower valley and a fair weather road traversing the upper valley. The total population is 354413 (1991 census) comprising predominantly illiterate rural farmers. The district has a 50 bed eye hospital that has been fully operational since 1989. The hospital performs approximately 600 cataract operations annually. Intracapsular cataract surgery with aphakic spectacle correction is the primary surgery of choice.

All the inhabitants aged 40-75 from 39 village administrative units and two town municipalities of Dang district were invited to have their vision examined by specially trained local health and social workers. Those who were identified with visual impairment were referred to mobile screening camps organised by the eye hospital. Those with presenting vision less than $6 / 60$ in the better eye as a result of cataract were invited to have cataract surgery. Transport from the nearest road to the hospital was provided free of cost; however, all patients were made aware of the 200 Nepalese rupees $(£ 2.30)$ charge for surgery. At the hospital, patients who met predetermined eligibility criteria were invited to participate in a study on cataract surgery. ${ }^{7}$ Those who chose not to participate in the study received the routine treatment of the eye hospital.

One year after the initial screening those who were between 40 and 75 years of age and had not undergone cataract surgery were visited by a team comprising one eye examiner and one interviewer. Each patient's vision was reexamined and the patient and his/her relative (husband, wife, son, or daughter) were interviewed. The sources of the questions for the interviews were taken from validated visual function and a quality of life questionnaire addressing the impact of visual impairment on physical and psychosocial functions. ${ }^{89}$

The interview included questions on visual function (Table 1), acceptance of cataract surgery in relation to socioeconomic variables, questions concerning self care, and self evaluated psychosocial esteem. The questionnaire was developed in English and then translated to Nepali and the local tribal language. The translated versions were field tested and final adjustments were made. The interviews were conducted by a public health officer. A translator for the local tribal language was used when necessary. 
Table 5 Reported need of assistance in everyday activities * because of vision loss

\begin{tabular}{|c|c|c|c|c|}
\hline & $\begin{array}{l}\text { All }(<6 / 18) \\
(n=96)\end{array}$ & $\begin{array}{l}\text { Visual impairment and } \\
\text { severe vision loss } \\
(<6 / 18-3 / 60)(n=47)\end{array}$ & $\begin{array}{l}\text { Blind } \\
(<3 / 60) \\
(n=49)\end{array}$ & \\
\hline & $n(\%)$ & $n(\%)$ & $n(\%)$ & $R R(95 \% C I) t$ \\
\hline \multicolumn{5}{|l|}{ Self care: } \\
\hline patient & $22(22.9)$ & $3(6.4)$ & $19(38.8)$ & $6.07(1.92-19.19)$ \\
\hline guardian & $22(24.2)$ & $4(9.1)$ & $18(38.3)$ & $4.21(1.55-11.48)$ \\
\hline agreement $\neq$ & 0.86 & 0.91 & 0.81 & \\
\hline \multicolumn{5}{|l|}{ toilet } \\
\hline patient & $9(9.4)$ & $1(2.1)$ & $8(16.3)$ & $7.6(1.0-59.0)$ \\
\hline guardian & $10(11.0)$ & $1(2.3)$ & $9(19.2)$ & $8.43(1.11-63.8)$ \\
\hline agreement & 0.95 & 1.0 & 0.89 & \\
\hline \multicolumn{5}{|l|}{ eating } \\
\hline patient & $5(5.2)$ & 0 & $5(10.2)$ & \\
\hline guardian & $9(9.9)$ & $1(2.3)$ & $8(17.0)$ & $7.49(0.98-57.47)$ \\
\hline agreement & 0.93 & 0.98 & 0.89 & \\
\hline \multicolumn{5}{|l|}{ dressing } \\
\hline patient & $10(10.4)$ & 0 & $10(20.4)$ & \\
\hline guardian & $10(11.0)$ & 0 & $10(21.3)$ & \\
\hline agreement & 0.96 & 1.0 & 0.91 & \\
\hline \multicolumn{5}{|l|}{$\begin{array}{l}\text { Mobility: } \\
\text { visit neighbour }\end{array}$} \\
\hline patient & $17(17.7)$ & $2(4.3)$ & $15(30.6)$ & $7.19(1.74-2.98)$ \\
\hline guardian & $21(23.1)$ & $1(2.3)$ & $20(42.6)$ & $18.72(2.62-133.71)$ \\
\hline agreement & 0.91 & 0.98 & 0.85 & \\
\hline \multicolumn{5}{|c|}{ work in field or go to market } \\
\hline patient & $25(26.0)$ & $3(6.4)$ & $22(44.9)$ & $7.03(2.25-22.0)$ \\
\hline guardian & $20(22.0)$ & $1(2.3)$ & $19(40.4)$ & $18.22(2.54-130.8)$ \\
\hline agreement & 0.92 & 0.95 & 0.89 & \\
\hline
\end{tabular}

${ }^{\star}$ Categories: 1, no problem; 2, a little problem; 3, some problem; 4, very problematic; ttest between vision groups. $\$$ Number of patients and guardians with equal responses/total.

EPI-INFO Version 6.04 was used for the statistical analysis. Categorical variables were tested with the $\chi^{2}$ test or Fisher's exact test. The data were analysed according to two vision groups: 1 , visual impairment and severe vision loss (WHO categories I and II = visual acuity less than $6 / 18$ and equal to or greater than $3 / 60$ in better eye); and 2 , blind (WHO category III-V = visual acuity less than $3 / 60$ in better eye). Agreement coefficients between patient and guardian were calculated by adding the number of patients and guardians with equal responses and dividing by total responders.

\section{Results}

In the initial screening exercise 9783 inhabitants were examined. Of these $524(5.6 \%)$ were blind in one eye and $413(4.5 \%)$ were blind in both eyes. Of these, 319 subjects were eligible for cataract surgery, 103 (32.3\%) men and 216 $(67.7 \%)$ women. Within 12 months 145 ( $45.5 \%)$ accepted surgery at the local eye hospital and six $(1.9 \%)$ had surgery at other hospitals. Table 2 shows the number of acceptors and non-acceptors of surgery by degree of visual impairment and by sex. The male population were more likely to accept surgery than females $(R R=1.31 ; 95 \% C I=1.04-1.67)$. This was due to a highly significant difference in the visually impaired group $(\mathrm{RR}=1.72$; $95 \% \mathrm{CI}=1.16-2.57)$. There was no statistically significant difference between sexes in the blind group $(\mathrm{RR}=1.17 ; 95 \% \mathrm{CI}=0.89-1.55)$. Of the acceptors $57.9 \%$ were blind compared with $32 \%$ of the non-acceptors ( $p<0.0001)$. The difference in acceptance of surgery between vision groups was highly significant $(\mathrm{RR}=1.74 ; 95 \% \mathrm{CI}=1.36-2.22)$.

Of the patients who did not accept cataract surgery after 1 year of the screening procedure, $11(3.4 \%)$ had died. Thirty nine $(12.2 \%)$ patients were over the age of 75 and were excluded for practical reasons. Of the 118 eligible for inclusion in the programme 15 were not traceable.

The visual screening was performed on the remaining 103 subjects. Of these, seven had a presenting vision better than $6 / 60$ and were excluded. Ninety six $(57.1 \%)$ of the nonacceptors were included for the interview. Sixty seven $(69.8 \%)$ were females and $91(94.8 \%)$ were illiterate. There were no significant differences between vision groups. Table 3 presents mean score of self reported visual function by vision groups. As expected the blind had a significantly poorer self reported visual function than the visually impaired group- $77.7 \%$ complained of limitations of daily activities;

Table 6 Reported psychosocial impairment ${ }^{\star}$ because of vision loss

\begin{tabular}{|c|c|c|c|c|c|c|}
\hline & \multirow{2}{*}{$\begin{array}{l}\text { All }+(<6 / 18) \\
(n=96)\end{array}$} & \multicolumn{2}{|c|}{$\begin{array}{l}\text { Visual impairment and severe } \\
\text { vision loss }(<6 / 18-3 / 60)(n=47)\end{array}$} & \multicolumn{2}{|c|}{ Blind $(<3 / 60)(n=49)$} & \multirow[b]{2}{*}{$p$ Value $\neq$} \\
\hline & & $n(\%)$ & Mean score (SD) & $n(\%)$ & Mean score (SD) & \\
\hline \multicolumn{7}{|c|}{$\begin{array}{l}\text { Social: } \\
\text { attending ceremony }\end{array}$} \\
\hline patient & $69(71.9)$ & $28(59.6)$ & $1.81(0.85)$ & $41(83.7)$ & $2.65(1.10)$ & 0.0017 \\
\hline guardian & $72(79.1)$ & $31(70.4)$ & $1.89(1.01)$ & $41(87.2)$ & $2.61(1.19)$ & 0.002 \\
\hline agreement $\$$ & 0.55 & 0.66 & & 0.45 & & \\
\hline \multicolumn{7}{|c|}{ meeting people } \\
\hline patient & $61(63.5)$ & $22(46.8)$ & $1.85(1.0)$ & $39(79.6)$ & $2.47(1.38)$ & 0.008 \\
\hline guardian & $68(74.7)$ & $29(65.9)$ & $1.62(0.8)$ & $39(83.0)$ & $2.35(0.99)$ & 0.0001 \\
\hline agreement & 0.55 & 0.66 & & 0.45 & & \\
\hline \multicolumn{7}{|c|}{$\begin{array}{l}\text { Psychological: } \\
\text { burden to others }\end{array}$} \\
\hline patient & $68(70.8)$ & $27(57.5)$ & $1.79(0.97)$ & $41(83.7)$ & $2.14(1.06)$ & 0.1 \\
\hline guardian & $65(71.4)$ & $29(65.9)$ & $1.86(0.88)$ & $36(76.6)$ & $2.49(1.0)$ & 0.002 \\
\hline agreement & 0.57 & 0.61 & & 0.53 & & \\
\hline \multicolumn{7}{|c|}{ feeling dejected } \\
\hline patient & $68(70.8)$ & $29(61.7)$ & $1.92(0.93)$ & $39(76.6)$ & $2.49(1.10)$ & 0.009 \\
\hline guardian & $39(42.9)$ & $29(65.9)$ & $1.81(0.95)$ & $10(21.3)$ & $2.10(1.10)$ & 0.25 \\
\hline agreement & 0.63 & 0.64 & & 0.62 & & \\
\hline \multicolumn{7}{|c|}{ loss of confidence } \\
\hline patient & $78(81.3)$ & $33(70.2)$ & $2.04(0.91)$ & $45(91.8)$ & $2.53(0.87)$ & 0.008 \\
\hline guardian & $59(64.8)$ & $28(63.6)$ & $1.81(0.99)$ & $31(66.0)$ & $1.84(0.97)$ & 0.88 \\
\hline agreement & 0.47 & 0.52 & & 0.43 & & \\
\hline
\end{tabular}

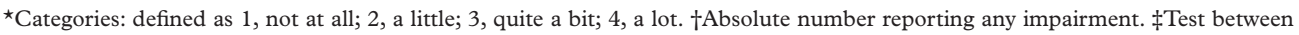
vision groups; Snumber of patients and guardians with equal responses/total. 
Table 7 Vision change 1 year after initial screening $(n=96)$

\begin{tabular}{|c|c|c|c|c|c|}
\hline \multirow{2}{*}{$\begin{array}{l}\text { Previous } \\
\text { vision }\end{array}$} & \multicolumn{5}{|c|}{ Present vision * } \\
\hline & $\operatorname{In}(\%)$ & II $n(\%)$ & III $n(\%)$ & $I V n(\%)$ & All $n(\%)$ \\
\hline I & $18(18.8)$ & $13(13.5)$ & $3(3.1)$ & 0 & $34(35.4)$ \\
\hline II & $1(1.0)$ & $12(12.5)$ & $14(14.6)$ & $1(1.0)$ & $28(29.2)$ \\
\hline III & $3(3.1)$ & 0 & $15(15.6)$ & $6(6.3)$ & $24(25.0)$ \\
\hline IV & 0 & 0 & 0 & $10(10.4)$ & $10(10.4)$ \\
\hline All & $22(22.9)$ & $25(26.0)$ & $32(33.3)$ & $17(17.7)$ & 96 \\
\hline
\end{tabular}

${ }^{\star}$ Categories (WHO): I=less than $6 / 18-6 / 60$; II=less than $6 / 60-3 / 60$; III=less than $3 / 60-1 / 60$ IV $=$ less than $1 / 60$ to perception of light; kappa statistic $=0.437, z=7.41, p<0.001$.

$83.3 \%$ and $42.8 \%$ had problems recognising people at distance and at near respectively; $59 \%$ had difficulties in identifying small objects; and $73.9 \%$ had problems adapting to darkness.

Table 4 presents self reported and the guardian reported reasons for not accepting surgery. Economic refers to costs as patient fees for surgery, loss of income during hospital stay, food, etc. Logistics refers to the guardian's willingness or capability to accompany the patient. Economic and logistical constraints were the two most important reasons given for not accepting surgery, $50 \%$ and $44.8 \%$ respectively. Other reasons given were fear of surgery $(33.3 \%)$ and lack of time because of harvesting and planting $(18.8 \%)$. These variables showed a good agreement between subject and guardian. There were no statistically significant difference between visions groups for any of these variables.

The reported need for assistance in everyday activities (Table 5) showed that only $22.9 \%$ needed help in bathing, $9.4 \%$ in going to the toilet, $5.2 \%$ in eating, and $10.4 \%$ in dressing. Over $17 \%$ had problems visiting neighbours and $26.0 \%$ in working in the field or going to the market; $77 \%$ did not need assistance in their daily activities (data not shown). There was good agreement between the subject and the guardian in reporting of these variables. There were significant differences between vision groups for all variables addressing daily activities. As expected those with the poorest vision reported more frequently the need for assistance than those with better vision $(\mathrm{p}<0.05)$.

Table 6 shows the degree of psychosocial impairment. There was a general perception in over half of the subjects of being a burden to the family, feeling dejected, and having lost self confidence. Analysis of the psychosocial functions showed significant differences between vision groups for most variables. Except for consideration of burden the group with poorest vision reported consistently poorer quality of life. For these variables there was a poorer agreement between the patient and guardian than what was found for variables addressing physical impairment. The guardian had a tendency to report a better psychosocial function than what was reported by the patient himself. For the patients there was no significant difference between the two vision groups in consideration of being a burden; however, the guardians perceived that those with poorer vision were significantly a greater burden than those with the better vision. Patients with poorer vision complained more frequently of being dejected than those with better vision. Their guardian, however, did not report such differences.

One year after the initial screening $37.5 \%$ had a further deterioration of vision $(\mathrm{p}<0.01)$ (Table 7). When asked again about the willingness to accept surgery $66.7 \%$ said they were now ready to have cataract surgery (Table 8); however, within 1 year of the interview only $24.0 \%$ had undergone treatment and there was no significant difference between vision groups. There was good agreement between self reported and guardian reported willingness to accept surgery.

\section{Discussion}

We have found in this population of illiterate farmers in rural Nepal that, even when offered free transport, under half the population accept surgery within 1 year. There was, in general, good agreement between what the patients and the relatives reported were reasons for not accepting surgery. There was also good agreement in perception of impairment of daily function and need for assistance in daily activities. As may have been expected, in answering questions concerning impairment of psychosocial functions, there was a poor agreement with the patients' perceptions of impairment being greater than the perception of the relatives.

Although a majority of the non-acceptors said they were willing to have surgery, even with the promise of free treatment, only $24 \%$ actually had surgery within the following year. For this population the promise of free surgery did not seem to be the main motivational factor to accept treatment. Other considerations such as the opportunity costs of being away from daily income earning activities together with the lack of the patient's own

Table 8 Self reported and guardian's reported agreement to surgery and acceptance of surgery by vision group

\begin{tabular}{|c|c|c|c|c|}
\hline & $\begin{array}{l}\text { All }(<6 / 18) \\
(n=96)\end{array}$ & $\begin{array}{l}\text { Visual impairment and severe } \\
\text { vision loss }(<6 / 18-3 / 60)(n=47)\end{array}$ & $\begin{array}{l}\text { Blind }(<3 / 60) \\
(n=49)\end{array}$ & \\
\hline Acceptance of surgery & $n(\%)$ & $n(\%)$ & $n(\%)$ & $p$ Value ${ }^{\star}$ \\
\hline \multicolumn{5}{|l|}{ Without economic incentive } \\
\hline Self reported & $64(66.7)$ & $29(61.7)$ & $35(71.4)$ & 0.77 \\
\hline Guardian & $69(71.9)$ & $30(63.8)$ & $39(79.6)$ & 0.72 \\
\hline Agreement & 0.93 & 0.97 & 0.90 & \\
\hline \multicolumn{5}{|l|}{ With economic incentive } \\
\hline Self reported & $59(61.5)$ & $29(61.8)$ & $30(61.2)$ & 0.96 \\
\hline Guardian & $64(66.7)$ & $28(60.0)$ & $36(73.5)$ & 0.15 \\
\hline Agreement & 0.92 & 0.97 & 0.83 & \\
\hline Surgery undertaken within 1 year of interview & $23(24.0)$ & $12(25.5)$ & $11(22.4)$ & 0.72 \\
\hline
\end{tabular}

*Test between vision groups. 
motivation seem to be more important. The costs and efforts needed to undergo treatment seem greater than the perceived value of visual rehabilitation. A substantial number of subjects had a perception of limitations of daily activity and impairment of visual and psychosocial function. That a majority of patients still retain enough vision to maintain personal hygiene, dress, eat independently, and retain enough mobility to get about and around the household, seems to be an important determinant for not accepting surgery. Over $77 \%$ of the 96 non-acceptors interviewed had no need of assistance in their everyday activities and therefore did not think surgery was required, signalling differences between the doctors' perceptions on indication for surgery and the perceptions of the patient and his/her relative(s).

Despite our finding that the female population is more likely to have visual impairment due to cataract than the men, for the group with visual impairment and severe vision loss it is the male population that more readily accepts surgery. This is probably the result of the differences in the roles of males and females of the age group affected, with the male population being more mobile and the female population being traditionally more confined to the household.

The Nepal blindness survey (1981) found the overall cataract surgical coverage (the number of aphakics in the population divided by the sum of the number of aphakics and unoperated cataract blind) to be $35 \%$. In the plains of the mid western region the surgical coverage was $32 \%$ (vision less than $3 / 60$ better eye). ${ }^{10} \mathrm{~A}$ follow up of this survey (1995) showed that the surgical coverage had increased by only $10 \%$ despite the existence of well established eye hospitals in the area. ${ }^{11}$ The utilisation of services was almost twice as great in the urban areas compared with the rural areas. This survey and previous studies ${ }^{12}$ indicate clearly that, even when there is awareness of the availability of treatment, it is the urban, affluent, and literate segments of the society that seek the services. In a study based on interviews with cataract patients in rural areas of Madurai, southern India, surgical acceptance was $13.6 \%$ for a group of patients who had surgery without any interventions or incentives, while with intervention and the full economic incentive, including free treatment and free eyeglasses, the acceptance was $33.3 \% .^{13}$ The cost of the procedure was not the principal deterrent to undergoing surgery but rather the lack of social support and a perception that the procedure was not needed, thus highlighting the wide gap existing between the medical community's perception of patient needs and patients' own perceptions of their needs. In our study in a typical farming population of rural Nepal, we found that with intense counselling and an offer of logistical support in the form of free transport, the surgical coverage was $46 \%$ (patients with vision less than $6 / 60$ better eye). This increased by $13 \%$ when further counselling and a economic incentive of offering free surgical treatment was included.

In the group of non-acceptors, the degree of visual impairment was not a determinant for having surgery (Table 8 ).

Increased surgical uptake will most likely be influenced first and foremost by changes in perceptions of the benefits of cataract surgery in the local community. This is influenced by the quality of previous surgery with resulting positive propaganda of the successfully operated cataract patients or aphakic motivator. In addition, as has also been shown in previous studies, factors like literacy and education are important determinants for accepting surgery. Medicine tends to be prescriptive based on technological advances that it is able to offer. Medical practice needs to develop a more holistic understanding of the needs of the communities cultivating a greater capability to analyse the role of cultural, social, and economic factors. ${ }^{14}{ }^{15}$ Next to the quality of services, it is likely that real changes in economic wealth and adult literacy in the communities, particularly in the female population, will be the most important determinants for improving the surgical uptake.

1 Thylefors B, Negrel AD, Pararajasegaram R, et al. Global data on blindness. Bull World Health Organ 1995;73:11521 .

2 Jose R, Bachani D. World Bank-assisted cataract blindness control project. Indian f Ophthalmol 1995;43:35-43.

3 Minassian DC, Mehra V. 3.8 Million blinded by cataract each year:projections from the first epidemiological study of incidence of cataract blindness. $\mathrm{Br} \quad \mathcal{F}$ Ophthalmol 1990;74:341-3.

4 Limburg H, Kumar R, Bachani D. Monitoring and evaluating cataract intervention in India. $\mathrm{Br} \mathcal{F}$ Ophthalmol 1996;80:951-5.

5 Padmashree G, Wenkataswamy MS, Brilliant G. Social and economic barriers to cataract surgery in rural south india: a preliminary report. Visual Impairment and Blindness December 1981:405-8.

6 Kupfer C. The International Agency for the Prevention of Blindness. Am f Ophthalmol 1994;117:253-7.

7 The South Asian Cataract Management Study Group. The south Asian cataract management study. I The first 662 cataract surgeries: a preliminary report. $\mathrm{Br} \mathcal{F}$ Ophthalmol 1995;79:1029-5.

8 Ellwein LB, Fletcher A, Negrel DA, et al. Quality of life assessment in blindness prevention interventions. Int $O p h$ thalmol 1995;18:263-8.

9 Fletcher EF, Ellwein LB, Selvaraj S, et al. Measurements of vision function and quality of life in patients with cataracts in southern India. Arch Ophthalmol 1997;115:767-73.

10 Seva Foundation. The epidemiology of blindness in Nepal. Report of the 1981 Nepal Blindness Survey;212-8.

11 Regmi G, Pokahrel GP. Cataract blindness prevalence in Bheri and Lumbini zones. Eye Care delivery and service outcomes in south Asia. XVI Congress of Asia Pacific Academy of Ophthalmology. 4 March 1997.

12 Brilliant GE, Brilliant LB. Using social epidemiology to understand who stays blind and who gets operated for cataract in a rural setting. Soc Sci Med 1985;21:553-8.

13 Brilliant GE, Lepkowski JM, Zurita B, et al. Social determinants of cataract surgery utilization in south India. Arch Ophthalmol 1991;109:584-9.

14 Helman CG. Culture, health and illness. Oxford: ButterworthHeinemann, 1994.

15 Coreil J, Mull D, eds. Anthropology and primary health care. Boulder, CO: Westview Press, 1990. 